\title{
La Ciencia ante la pandemia
}

Son tiempos de afección a los sistemas de salud, pública y privada, a la sociedad, a la economía y a la forma de vida de cada ciudadano del planeta. Las condiciones adversas que presenta la crisis mundial que vivimos, el desempleo y, el no tener certeza de cómo proceder, ha empujado a empresarios y particulares, a actuar de forma impetuosa, adaptándose a los constantes y vertiginosos cambios como jamás se ha visto en el pasado, y por supuesto, las consecuencias son notorias y claras; en pérdidas no solo de la fortaleza de las economías sino de cuantiosas vidas humanas. En tiempos desesperados, son la Académica y la Ciencia los llamados a mantener la calma, a estudiar las variables que afectarán a las acertadas decisiones del futuro y a dar luz en medio de la obscuridad. El método científico ha probado ser el camino correcto para la consecución de los objetivos, que, aunque cambian al ritmo que marca la sociedad, se mantiene en la necesidad de respuestas acertadas.

Al hablar de crisis, también se habla de creatividad, inventiva e innovación. No habrá período en el que la ciencia y el saber avance y se desarrolle más, que en estos tiempos y aquellos que serán conocidos como, de recuperación.

Se exhorta a los investigadores del mundo a unirse en un único esfuerzo mancomunado para salir de esta crisis. Trabajar para guiar y dar luz, en lugar de la búsqueda de un ranking de publicación. Se invita a pensar en un mundo en donde se vea a grandes masas actuar por el beneficio propio al igual que otros que luchan con total desinterés porque han comprendido que solo juntos superaremos al COVID-19, busquemos el camino para lograr que el mundo que quede en la post pandemia, sea un mundo mejor.

\section{lng. Diego Patricio Cisneros Quintarilla. Mgs. \\ Universidad Católica de Cuenca Ecuador https://orcid.org/0000-0003-0897-8938}

